\title{
Conventional Videoendoscopy and Endoscopic Findings Related to Helicobacter Pylori
}

\author{
Alexandre Gomes ${ }^{1,2 *}$, Thelma Larocca Skare ${ }^{1}$ \\ ${ }^{1}$ Postgraduate Program in Principles of Surgery, Evangelic Faculty of Paraná/University Evangelic Hospital of Curitiba/Medical \\ Research Institute, Curitiba, PR \\ ${ }^{2}$ Gastrointestinal Endoscopy Service of the 9 of July Hospital, São Paulo, SP, Brazil \\ *Corresponding Author: Alexandre Gomes, Postgraduate Program in Principles of Surgery, Evangelic Faculty of Paraná/Uni- \\ versity Evangelic Hospital of Curitiba/Medical Research Institute, Curitiba, PR, Gastrointestinal Endoscopy Service of the 9 of July \\ Hospital, São Paulo, SP, Brazil, Tel: +55 32334873; E- mail: alex-gomes@uol.com.br
}

\begin{abstract}
Background: Studies with the latest technologies such as endoscopy with magnification and chromo endoscopy showed that various endoscopic aspects are clearly related to infection by Helicobacter pylori (HP). The description of different patterns of erythema in gastric body under magnification of images revived interest in identifying these patterns by standard endoscopy.

Aim: Validate endoscopic aspects related to HP found in conventional video gastroscopy, allowing the predictability of the diagnosis as well as proper targeting biopsies. Methods: Prospective study of 339 consecutive patients with the standard video endoscope image analysis were obtained, recorded and stored in a program database. These images were studied with respect to the presence or absence of HP, diagnosed by rapid urease test and/or by histological analysis. Were studied:

a) normal mucosa appearance

b) mucosal nodularity

c) diffuse nonspecific erythema or redness of antrum and body

d) mosaic pattern with focal area of hyperemia

e) erythema in streaks or bands (red streaks)

f) elevated (raised) erosions

g) flat erosions

h) fundic gland polyps.

The main exclusion criteria were the use of drugs, HP pre-treatment and other entities that could affect results.

Results: Applying the exclusion criteria, were included 170 of the 339 patients, of which 52 (30.58\%) were positive for HP and 118 negative. On the positive findings, the most associated with infection were: antral nodularity (26.92\%); raised erosion $(15.38 \%)$ and mosaic pattern in the body $(21.15 \%)$. On the negative group the normal appearance of the mucosa was $66.94 \%$; red streaks in $9.32 \%$; flat erosions $11.86 \%$; and fundic gland polyps $11.86 \%$.

Conclusion: Endoscopic findings are useful in predicting the outcome, localization and targeting of biopsies in gastritis related to HP infection. The most representative form of HP related gastritis was the nodularity of the antral mucosa. The raised erosion and mosaic pattern in the body are suggestive but not specific to the infection. Normal-appearing forms, red streaks and fundic gland polyposis are related to the negativity of HP infection. The other forms were not conclusive of the presence of HP.
\end{abstract}

Received Date: September 12, 2017

Accepted Date: September 24, 2017

Published Date: October 02, 2017

Citation: Alexandre Gomes., et al. Conventional Videoendoscopy and Endoscopic Findings Related to Helicobacter Pylori. (2017) J Gastrointest Disord Liver Func 3(1): 104- 108.

DOI: $10.15436 / 2471-0601.17 .1683$

Keywords: Helicobacter pylori; Gastritis; Endoscopy, Gastrointestinal

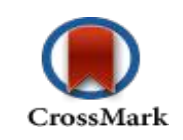




\section{Introduction}

Since the discovery of Helicobacter pylori (HP) in 1981, strong evidences have indicated that the infection has an important role in the pathogenesis of chronic gastritis, peptic ulcer and gastric cancer ${ }^{[1]}$. Gastritis involves cell damage, regenerative and inflammation of the mucosa, with presence of lymphoid follicles. The inflammatory process is initially superficial but, in sequence, affects the entire mucosa, first in the antrum and progressing proximally to the body. Over the years, the gastric glands are destroyed showing epithelial atrophy and intestinal metaplasia areas that favor the appearance of gastric carcinoma $^{[2]}$.

The diagnosis of the infection requires at least two tests in accordance with the European guidelines ${ }^{[3]}$. The most used are the rapid urease test and histological analysis ${ }^{[4]}$. The rapid urease test has a sensitivity of $92 \%$ and specificity of $95 \%{ }^{[5]}$. Laine et $a^{\left[l^{[6]}\right.}$ found histological sensitivity variation in the identification of HP bacteria according to the bacterial density in the sample. The $\mathrm{H} \& \mathrm{E}$ staining showed $70 \%$ to $98 \%$ of sensitivity and specificity of $89 \%$ to $98 \%$ in the identification of HP and Giemsa sensitivity of $64 \%$ to $96 \%$ and specificity of $98 \%$ to $100 \%{ }^{[6]}$. HP is distributed irregularly in gastric mucous epithelial surface and the relatively low density of bacteria in various groups of patients can lead to false-negative results in methods of biopsy ${ }^{[7]}$.

There are few reports in the literature regarding endoscopic patterns of related HP gastritis using conventional endoscopy. In the initial studies in 1995, some authors concluded that it was not possible to establish this diagnosis based only on endoscopy ${ }^{[8,9]}$.

However, newer technologies such as magnification and chromo endoscopy ${ }^{[1,12]}$ have shown that there are endoscopic features that are clearly associated with HP infection, while other endoscopic features are related to non-infected cases or cases in which the infection has already been eradicated ${ }^{[10]}$.

Yagi et a ${ }^{[13,14]}$ described the characteristics of endoscopic findings with magnification in the gastric body with normal appearance and negative HP: erythema in tiny streaks or spots in "pinhole" aspect, which correspond to sub epithelial capillaries and venules networks called RAC (Regular Arrangement of Collecting venules). Anagnostopoulos et a ${ }^{[15]}$ demonstrated the usefulness of magnifying endoscopy in the identification of H. pylori-associated gastritis. Yan et al ${ }^{[31]}$ showed that mucosal patterns in $H$. pylori-infected gastric mucosa without atrophy can be reliably identified using standard endoscopy in the gastric corpus. CHO et a ${ }^{[19]}$ using standard endoscopy showed that mosaic pattern with spotty erythema was a reliable predictor of H. pylori infection. Mosaic-like appearance or speckled enanthem in the gastric body is related to infection by HP, as also the erythema in association with swelling of folds and exudate, indicating intense active inflammatory process. Erythema in streaks or bands in the antrum and the appearance of tiny red spots in the body (corresponding to subepithelial collecting venules, a normal condition) are associated with the absence of infection by HP. These authors suggest that, using this technique, pathology is not required ${ }^{[15]}$.

However, magnification and chromo endoscopy it is not available in most diagnostic centers, but also demand more time for execution and learning and do not seem to be practical in daily routine examinations. If specific patterns of HP status can be identified using conventional endoscopy, these standards could be applied to predict and select patients and biopsies could be directed to areas suspected of being infected by HP.

This study aims to verify the validity of the recognition of morphological patterns associated with or without HP infection using conventional endoscopy, which would be helpful to favor the targeting of biopsies for the most affected areas.

\section{Methods}

This is an observational cross-sectional study approved by the ethics committee in local research. In this study, the endoscopic findings of 339 consecutive patients from May $27^{\text {th }} 2015$ until July $10^{\text {th }}, 2015$ in Endoclinic, SP, Brazil were analyzed, prospectively. Free and informed consent was obtained from all participants.

The included underwent endoscopy unit with Fujinon 4400 or Pentax EPM 3500 and all tests performed by a single professional. Sedation was carried out with 25 to 50 ug fentanolamina and midazolam $2-5 \mathrm{mg}^{[17]}$. Images were recorded and saved in the database (OCRAM $₫$ system, SP) being obtained of 12 - 20 images per patient in all cases. These were selected for this review 6 - 8 images. Endoscopic aspects that were evaluated were: normal mucosa appearance, nonspecific diffuse erythema of antrum and body, erythema in streaks or bands (red streaks), mosaic-like appearance in the gastric body, flat erosions (minor surface defects $5 \mathrm{~mm}$ and flat edges), elevated (raised) erosions, nodularity of the mucosa and fundic gland polyps (Figures 1 and 2).

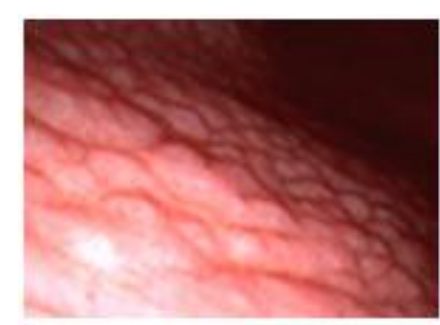

A

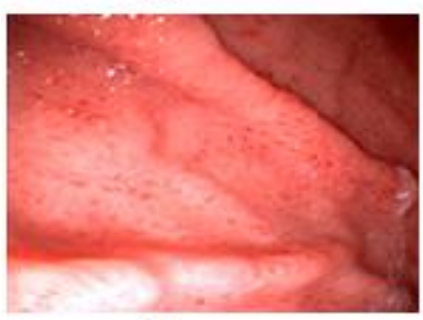

C

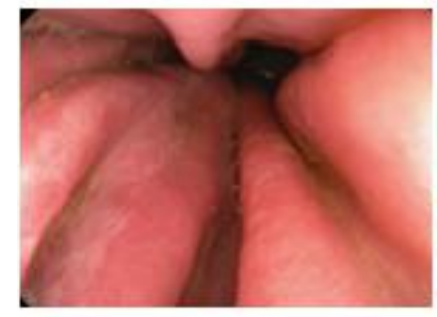

$\mathbf{E}$

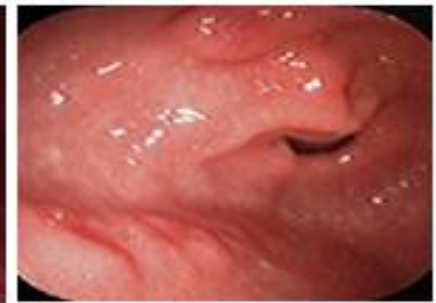

B

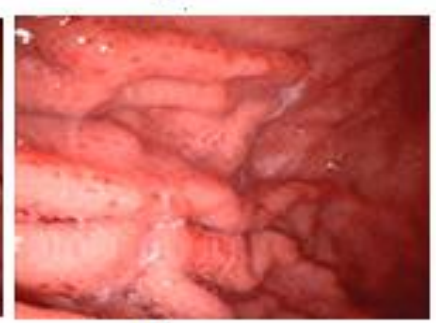

D

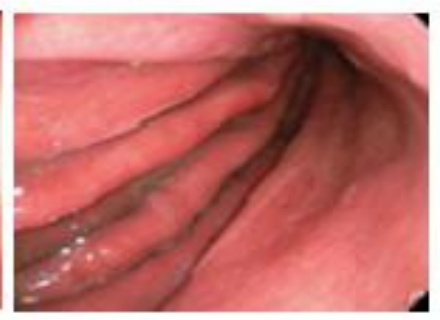

$\mathbf{F}$
Figure 1: Endoscopic findings related to the positive HP: A) antral nodularity; B) raised erosions; $\mathrm{C}$ and D) gastric body with spotty redness or mosaic mucosal pattern; $\mathrm{E}$ and F) diffuse erythema with edema of gastric folds and thin layer of exudate. 


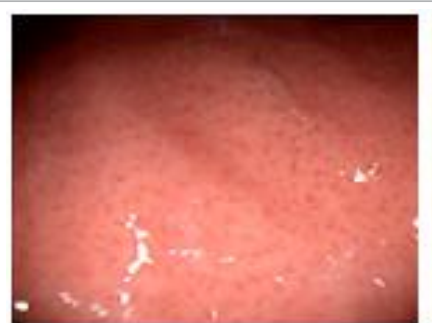

A

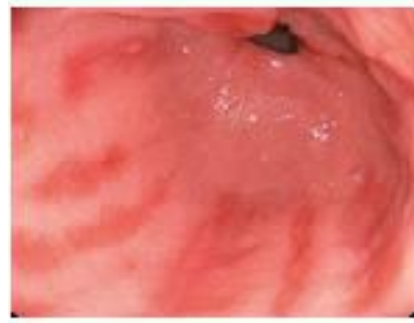

C

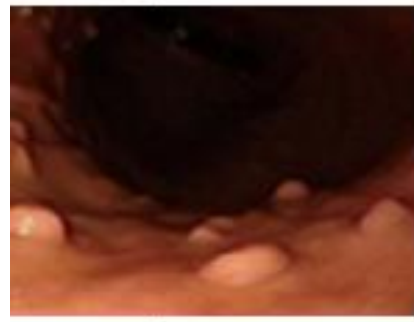

$\mathbf{E}$

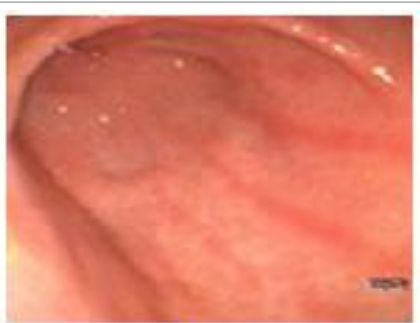

B

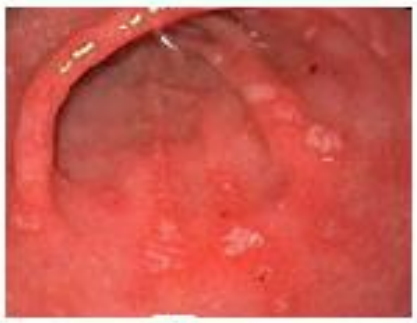

D

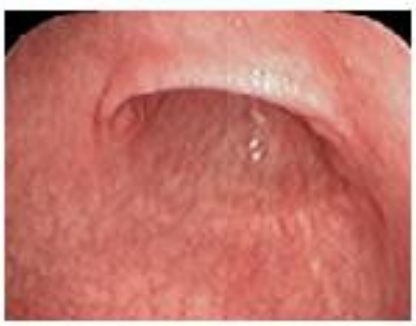

F
Figure 2: Endoscopic findings related to negative HP: A) normal appearance of the gastric body with regular arrangement of collecting venules; B) erythema in streaks or bands (red streaks); C) red streaks with flat erosions; D) flat erosions in the antrum; E) fundic gland polyps; F) extensive mucosal atrophy.

The diagnosis of HP infection was done by the urease tests (UretestRenylab $\left.{ }^{\circledR}, M G\right)$ performed with at least two fragments from the antrum and two from the body. The positive histological fragments were subjected to histological examination by Hematoxylin and Eosin (HE) staining and Giemsa stain to identify the HP, made by a pathologist who was blinded to the other results.

The following exclusion criteria were: patients with anemia, liver cirrhosis, gastric cancer, gastrectomy, renal failure, congestive heart failure, recent use of anti-inflammatory drugs, aspirin, anti-thrombotics, use of proton pump inhibitors or H2-receptor antagonists in past two months, prior history of eradication of HP; extensive gastric mucosal atrophy.

Applied exclusion criteria were eliminated 169 patients, leaving 170 , of which 52/170 (30.5\%) were positive and 118/170 (69.4\%) HP negative.

The data were studied in frequency tables and contingency being used the Fisher test and chi-square association for nominal data and Mann-Whitney and unpaired t test for association of numerical data. The significance used was $5 \%(p=0.05)$. The calculations were made with the Graph Pad Prism version 5.0 software.

\section{Results}

The positive HP endoscopic findings are shown in Table 1 where it can be seen that the most frequent finding was diffuse redness. In Table 2 is the frequency of the findings in the negative group.

Table 1: Endoscopic findings in 52 patients positive for HP infection.

\begin{tabular}{|l|c|c|}
\hline Findings & $\mathbf{n = 5 2}$ & $\mathbf{\%}$ \\
\hline Normal mucosa appearance & 8 & 15,38 \\
\hline Antral nodularity & 14 & 26,92 \\
\hline Mosaic pattern in the body & 11 & 21,15 \\
\hline Diffuse redness & 30 & 57,69 \\
\hline Red streaks & 0 & 0 \\
\hline Flat erosions & 5 & 9,61 \\
\hline Elevated (raised) erosions & 8 & 15,38 \\
\hline Fundic gland polyps & 0 & 0 \\
\hline
\end{tabular}

Table 2: Endoscopic findings in 118 patients negative for Helicobacter Pylori infection.

\begin{tabular}{|l|c|c|}
\hline Findings & $\mathbf{n = 1 1 8}$ & $\mathbf{\%}$ \\
\hline Normal mucosa appearance & 79 & 66,94 \\
\hline Antral nodularity & 0 & 0 \\
\hline Mosaic pattern in the body & 3 & 2,54 \\
\hline Diffuse redness & 23 & 21,18 \\
\hline Red streaks & 14 & 11,86 \\
\hline Flat erosions & 0 & 0 \\
\hline Elevated (raised) erosions & 11 & 9,32 \\
\hline Fundic gland polyps & 14 & 11,86 \\
\hline
\end{tabular}

Table 3: Comparison of endoscopic findings in HP positive and negative individuals.

\begin{tabular}{|l|l|l|l|l|l|}
\hline Variable & HP positive $\mathbf{n}=\mathbf{5 2}$ & HP negative $\mathbf{n}=\mathbf{1 1 8}$ & $\mathbf{p}$ & OR & CI \\
\hline Age years) & $\begin{array}{l}15-80 \text { Average of } \\
41.15 \pm 14.84\end{array}$ & $\begin{array}{l}9,0-72,0 \text { Average of } \\
41.14 \pm 15.45\end{array}$ & $0,99(*)$ & & \\
\hline Genre & 32 women $/ 26 \mathrm{men}$ & 72 mulheres/ $46 \mathrm{men}$ & $0,45(\S)$ & & \\
\hline Normal appearance & $8(15,38 \%)$ & $79(66,94 \%)$ & $<0,0001(\S \S)$ & 0,08 & $0,03-0,20$ \\
\hline Nodularity & $14(26,92 \%)$ & 0 & $<0,0001(\S \S)$ & OR $=89,26$ & $95 \% \mathrm{CI}=5.19-153$ \\
\hline Mosaic pattern & $11(21,15 \%)$ & $3(2,54 \%)$ & $0,0002(\S \S)$ & OR $=10,28$ & $95 \% \mathrm{CI}=2,73-38,7$ \\
\hline Diffuse redness & $30(57,69 \%)$ & $25(21,18 \%)$ & $<0,0001(\S)$ & OR $=5,07$ & $95 \% \mathrm{CI}=2,50-10,27$ \\
\hline Flat erosions & $5(9,61 \%)$ & $14(11,86 \%)$ & $0,33(\S)$ & & \\
\hline Raised erosions & $8(15,38 \%)$ & 0 & $0.008(\S \S)$ & OR $=21.9$ & $95 \% \mathrm{CI}=1,16-416$ \\
\hline Red streaks & 0 & $11(9,32 \%)$ & $0,01(\S \S)$ & OR $=0,089$ & $95 \% \mathrm{CI}=0,005-1,54$ \\
\hline Polyps & 0 & $14(11,86 \%)$ & $0,005(\S \S)$ & OR $=0.06$ & $95 \% \mathrm{CI}=0,004-1,17$ \\
\hline
\end{tabular}


In about 8/52 (15.38\%) infected patients endoscopic examination was normal, while normality was present in 79/118 (66.94\%) of the uninfected. Comparing the endoscopic findings in Table 3, it is possible to note that patients with HP infection have more antral nodularity, mosaic pattern in the gastric body and redness of antrum and body.

\section{Discussion}

In the present study, endoscopic findings related to HP infected or uninfected gastric mucosa was identified. The selected endoscopic findings for this research have clear association with HP related gastritis and have been described in previous papers. swelling of folds, with or without exudate, diffuse or patchy erythema are regarded as mucosal inflammatory process and are good indicators of the presence of $\mathrm{HP}^{[18]}$.

Atrophic gastritis areas were avoided for biopsies in this study because they are hostile regions of the mucosa to the colonization of HP, causing false-negative test results and are present in older patients with longtime HP chronic infection ${ }^{[19]}$.

Magnifying studies have shown that the numerous tiny lines or red dots in the gastric body, seen with conventional endoscopy, were Regular Arrangement of Collecting venules (RAC), characteristic finding in normal stomach without HP infection, with $100 \%$ sensitivity and $90 \%$ specificity ${ }^{[14]}$.

In the current study the following imaging findings showed a positive association with HP: antral nodularity, mosaic pattern in the body, diffuse redness and raised erosion.

According to the literature, the antral nodularity is significantly associated with chronic active gastritis and follicular gastritis and showed high specificity $(98.5 \%)$ and high positive predictive value $(91.7 \%)$ but low sensitivity (32\%) for the diagnosis of $\mathrm{HP}^{[8,20]}$. In this research these images shown to be 89.2 times more frequent in infected individuals $(\mathrm{OR}=89.26$ and $95 \% \mathrm{CI}=5.19-153$ ) demonstrating that this finding is valuable in the diagnosis of HP infection and the endoscopic finding that best showed this association.

The raised erosions are mucosal elevations on gastric folds of the antrum and distal body containing fibrin exudation and sometimes hematin. Denote chronic inflammation and besides being frequent in patients with HP, appear also in individuals with chronic use of anti-inflammatory drugs ${ }^{[21]}$. In this research the findings were nearly 22 times more common in infected patients and none in the negative group $(\mathrm{p}=0.0081$, OR $=21,99 ; 95 \% \mathrm{CI}=1.16$ to 416.6 ).

The flat erosions are mucosal continuity solutions, associated with erythema, fibrin and sometimes hematin. In general, it is smaller than $5 \mathrm{~mm}$ in diameter and less than $1 \mathrm{~mm}$ depth $^{[21]}$. These images were not useful for the diagnosis in question. They represented $9.61 \%$ of HP positive group and $11.86 \%$ of HP negative group, with $\mathrm{p}=0.33$.

The redness of the mucosa was the most common finding. For this search, this kind of image was divided into diffuse redness in antrum and body, red strikes (according to the literature is found most negative HP cases) and mosaic pattern (more related in the HP positive cases $)^{[18]}$. In this study, diffuse redness was found in 30 patients in positive group HP (57.69\%) and in negative group $25(21.18 \%)$, being 5.7 times more common in infected individuals $(\mathrm{p}<0.0001, \mathrm{OR}=5.07,95 \% \mathrm{CI} 2.50$ to 10.27). The mosaic pattern was found in 11 patients in positive group $(21.15 \%)$ and in only three patients $(2.54 \%)$ in the negative group $(\mathrm{p}=0.0002 ; \mathrm{OR}=10.28 ; 95 \%$ CI 2.73 to 38.7 in $)$.

Red streaks findings have shown negative association with infection and this association was confirmed by analyzing the confidence interval obtained. On the negative HP group were found 11 patients with this aspect $(9.32 \%)$ and none in HP positive group $(\mathrm{p}=0.01 ; \mathrm{OR}=0.08995 \% \mathrm{CI}=0.005$ to 1.54$)$.

Fundic gland polyps, according to literature ${ }^{[22,23]}$ are associated only with uninfected cases. In this work all detected polyps are fundic gland and in all cases HP was negative $(n=14$; $11.86 \%$ ). No hyperplastic polyp (associated with the presence of HP and with congestive gastropathy) was found and no adenomatous polyp (associated with intestinal metaplasia).

Fundic gland polyps, red streaks and normal mucosal appearance correlate with the negativity of HP infection as other studies $^{[19,22,23]}$.

\section{Conclusion}

Endoscopic findings are useful in the predictability of the location and direction of biopsies in HP's research. The collection of mucosa fragments in the supposedly positive or negative cases and confirmed by rapid urease test avoids sending routinely for histology in cases of specific morphological patterns.

In the present study, the most representative form of HP related gastritis was the nodularity of the antral mucosa. The raised erosion and mosaic-like appearance in the body were suggestive but not specific to the infection. Fundic gland polyps, red streaks and normal mucosal appearance correlate with the negativity of HP infection. The other forms, diffuse nonspecific erythema or redness of antrum and body and flat erosions, were not conclusive of the presence or absence of HP.

\section{Conflict of Interest: none}

\section{Funding: None}

\section{References}

1.Komoto, K., Haruma, K., Kamada T., et al. Helicobacter pylori infection and gastric neoplasia: correlations with histological gastritis and tumor histology. (1998) Am J Gastroenterol 93(8): 1271-1276.

PubMed | Crossref | Others

2.Mihara, M., Haruma, K., Kamada, T., et al. The role of endoscopic findings for the diagnosis of Helicobacter pylori infection: evaluation in a country with high prevalence of atrophic gastritis. (1999) Helicobacter 4(1): 40-48.

PubMed | Crossref | Others

3. Malfertheiner, P., Mégraud, F., O'Morain, C., et al. Current concepts in the management of Helicobacter pylori infection - the Maastricht 2-2000 Consensus Report. (2002) Aliment Pharmacol Ther 16(2): 167180.

PubMed | Crossref | Others

4. Morais, M., Macedo, E.P., Silva Junior, M.R., et al. Comparação entre testes invasivos para o diagnóstico da infecção pelo Helicobacter pylori. (1997) Arq Gastroenterol 34(4): 207-211.

PubMed | Crossref $\mid$ Others

5. Ornellas, L.C., Cury, M.S., de Lima, V.M., et al. Avaliação do teste rápido da urease conservado em geladeira. (2000) Arq Gastroenterol 37(3): 155-157.

PubMed | Crossref| Others 
6. Laine, L., Lewin, D.N., Naritoku, W., et al. Prospective comparison of H\&E, Giemsa, and Genta stains for the diagnosis of Helicobacter pylori. (1997) Gastrointest Endosc 45(6): 463-467.

PubMed|Crossref| Others

7. Khulusi, S., Mendall, M.A., Patal, P., et al. Helicobacter pylori infection density and gastric inflammation in duodenal ulcer and non-ulcer subjects. (1995) Gut 37(3): 319-324.

PubMed | Crossref | Others

8. Bah, A., Saraga, E., Armstrong, D., et al. Endoscopic features of Helicobacter pylori-related gastritis. (1995) Endoscopy 27(8): 593-596.

PubMed | Crossref | Others

9. Redéen, S., Petersson, F., Jönsson, K.A., et al. Relationship of gastroscopic features to histological findings in gastritis and Helicobacter pylori infection in a general population sample. (2003) Endoscopy 35(11): 946-950.

PubMed | Crossref | Others

10. Gonen, C., Simsek, I., Sarioglu, S., et al. Comparison of high resolution magnifying endoscopy and standard video endoscopy for the diagnosis of Helicobacter pylori gastritis in routine clinical practice: a prospective study. (2009) Helicobacter 14(1): 12-21.

PubMed | Crossref| Others

11. Assirati, F.S., Hashimoto, C.L., Dib,R.A., et al. High definition endoscopy and "narrow band imaging" in the diagnosis of gastroesophageal reflux disease. (2014) Arq Bras Cir Dig 27(1): 59-65.

PubMed | Crossref| Others

12. Ratin, A.C.F., Orso, I.R.B. Minimal endoscopic changes in non-erosive reflux disease. (2015) Arq Bras Cir Dig 28(1): 20-23.

PubMed | Crossref | Others

13. Yagi, K., Nakamura, A., Sekine, A. Comparison between magnifying endoscopy and histological, culture and urease test findings from the gastric mucosa of the corpus. (2002) Endoscopy 34(5): 376-381. PubMed | Crossref| Others

14. Yagi, K., Nakamura, A., Sekine, A. Characteristic endoscopic and magnified endoscopic findings in the normal stomach without Helicobacter pylori infection. (2002) J Gastroenterol Hepatol 17(1): 39-45.

PubMed | Crossref| Others

15. Anagnostopoulos, G.K., Yao, K., Kaye, P., et al. High-resolution magnification endoscopy can reliably identify normal gastric mucosa, Helicobacter pylori associated gastritis, and gastric atrophy. (2007) Endoscopy 39(3): 202-207.

PubMed | Crossref | Others

16. Ji, R., Li, Y.Q. Diagnosing Helicobacter pylori infection in vivo by novel endoscopic techniques. (2014) World J Gastroenterol 20(28): 9314-9320.

PubMed | Crossref | Others

17. Leslie, K., Stonell, C.A. Anesthesia and sedation for gastrointestinal Endoscopy. (2005) Curr Opin Anaesthesiol 18: 431-436.

PubMed | Crossref $\mid$ Others

18. Watanabe, K., Nagata, N., Nakashima, R., et al. Predictive findings for Helicobacter pylori -uninfected, -infected and -eradicated gastric mucosa: Validation study. (2013) World J Gastroenterol 19(27): 43744379.

PubMed | Crossref | Others

19. Cho, J.H., Chang, Y.W., Jang, J.Y., et al. Close observation of gastric mucosal pattern by standard endoscopy can predict Helicobacter pylori infection status. (2013) J Gastroenterol Hepatol 28(2): 279-284. PubMed | Crossref | Others

20. Laine, L., Cohen, H., Sloane, R., et al. Interobserver agreement and predictive value of endoscopic findings for $H$. pylori and gastritis in normal volunteers. (1995) Gastrointest Endosc 42(5): 420-423.

PubMed | Crossref| Others

21. Appelman, H.D. Gastritis: terminology, etiology, and clinicopathological correlations: another biased view. (1994) Hum Pathol 25(10): 1006-1019.

PubMed |Crossref | Others
22. Sakai, N., Tatsuta, M., Hirasawa, R., et al. Prevalence of Helicobacter pylori infection in patients with hamartomatous fundic polyps. (1998) Dig Dis Sci 43: 766-772.

PubMed | Crossref|Others

23. Elhanafi, S., Saadi, M., Lou, W., et al. Gastric polyps: Association with Helicobacter pylori status and the pathology of the surrounding mucosa, a cross sectional study. (2015) World J Gastrointest Endosc 7(10): 995-1002.

PubMed | Crossref | Others

24. Kato, T., Yagi, N., Kamada, T., et al. Diagnosis of Helicobacter pylori infection in gastric mucosa by endoscopic features: a multicenter prospective study. (2013) Dig Endosc 25(5): 508-518.

PubMed | Crossref| Others

25. Dixon, M.F., Genta, R.M., Yardley, J.H., et al. Classification and Grading of Gastritis: The Updated Sydney System in the International Workshop on the Histopathology of Gastritis, Houston 1994. (1996) Am J Surg Pathol 20(10): 1161-1181.

PubMed |Crossref| Others

26. Loffeld, R.J. Diagnostic value of endoscopic signs of gastritis: with special emphasis to nodular antritis. (1999) Neth J Med 54(3): 96-100. PubMed | Crossref| Others

27. Misra, S.P., Dwivedi, M., Misra, V., et al. Endoscopic and histologic appearance of the gastric mucosa in patients with portal hypertension. (1990) Gastrointest Endosc 36(6): 575-579.

PubMed | Crossref|Others

28. Zerbib, F., Vialette, G., Cayla, R., et al. Follicular gastritis in adults. Relations with Helicobacter pylori, histological and endoscopic aspects. (1993) Gastroenterol Clin Biol 17(8-9): 529-534.

PubMed |Crossref|Others

29. Watanabe, M., Kato, J., Inoue, I., et al. Development of gastric cancer in nonatrophic stomach with highly active inflammation identified by serum levels of pepsinogen and Helicobacter pylori antibody together with endoscopic rugal hyperplastic gastritis. (2012) Int J Cancer 131(11): 2632-2642.

PubMed |Crossref|Others

30. Lopes, A.I., Vale, F.F., Oleastro, M. Helicobacter pylori infection recent developments in diagnosis. (2014) World J Gastroenterol 20(28): $9299-9313$.

PubMed | Crossref | Others

31. Yan, S.L., Wu, S.T., Chen, C.H., et al. Mucosal patterns of Helicobacter pylori-related gastritis without atrophy in the gastric corpus using standard endoscopy. (2010) World J Gastroenterol 16(4): 496-500. PubMed |Crossref|Others

32. Magalhães, M.A., Barbosa, A.J., Figueiredo, J.A., et al. Effects of different periods of gastric ischaemia in the viability of the tissue of body, fundus and antrum region of rabbit stomach. (2015) Arq Bras Cir Dig 28(3): 167-170.

PubMed | Crossref | Others

33. Henry, M.A. Diagnosis and management of gastroesophageal reflux disease. (2014) Arq Bras Cir Dig 27(3): 210-215.

PubMed | Crossref | Others

34. Bahú, M.G., Silveira, T.R., Maguilnick, I., et al. Endoscopic nodular gastritis: an endoscopic indicator of high-grade bacterial colonization and severe gastritis in children with Helicobacter pylori. (2003) J Pediatr Gastroenterol Nutr 36(2): 217-222.

PubMed | Crossref| Others

35. Calabrese, C., Di Febo, G., Brandi, G., et al. Correlation between endoscopic features of gastric antrum, histology and Helicobacter pylori infection in adults. (1999) Ital J Gastroenterol Hepatol; 31(5): 359365.

PubMed | Crossref | Others 